\title{
The changing shape of the ISCEV standard pattern onset VEP
}

\author{
Dorothy A. Thompson - Dennis M. Fritsch - Sharon E. Hardy - The POW Study Group
}

Received: 23 March 2017/Accepted: 25 May 2017/Published online: 13 June 2017

(C) The Author(s) 2017. This article is an open access publication

\begin{abstract}
Purpose Pattern onset VEPs do not always show distinct $\mathrm{C} 1-\mathrm{C} 2-\mathrm{C} 3$ peaks and troughs. Our purpose was to study changes in pattern onset VEP with age to determine when the illustrated ISCEV standard onset VEP waveform can be reliably recorded.

Methods We recorded pattern onset VEPs from an $\mathrm{Oz}$ electrode referred to mid-frontal electrode according to ISCEV standards by presenting checks of $60^{\prime}$ and $15^{\prime}$ side length in a $15^{\circ}$ field. Twenty-four adults aged 20-63 years participated. Amplitudes and latencies were collated. Pattern onset adult VEP shapes were compared to the waveform published in the ISCEV VEP standard and to paediatric pattern onset VEP waveforms recorded from 16 infants aged 7 months.

Results The shape of the pattern onset VEP changed gradually with age. The $\mathrm{C} 1-\mathrm{C} 2-\mathrm{C} 3$ morphology of the ISCEV standard pattern onset VEP becomes apparent consistently after 40 years to $60^{\prime}$ check stimulation. As age increases a negative trough, $\mathrm{C} 2$ is more frequently
\end{abstract}

D. A. Thompson $(\bowtie) \cdot$ D. M. Fritsch · S. E. Hardy The Tony Kriss Visual Electrophysiology Unit, Clinical and Academic Department of Ophthalmology, Great Ormond Street Hospital for Children, Great Ormond Street, London WC1N 3JH, UK

e-mail: dorothy.thompson@gosh.nhs.uk

D. A. Thompson · D. M. Fritsch

UCL Great Ormond Street Institute of Child Health , 30

Guilford Street, London WC1N 1EH, UK seen; however, the broad positive peak which characterises infant onset VEPs may still be recorded at 20 years. The group median measurements of onset VEPs to $60^{\prime}$ were $\mathrm{C} 17 \mu \mathrm{V} @ 88 \mathrm{~ms}$ (range 67-110 ms), C2 $9 \mu \mathrm{V} @ 109 \mathrm{~ms}$ (range 89-158 ms) and C3 $13 \mu \mathrm{V} @ 121-246$ ms. To smaller 15' checks, peak latencies were earlier and C2 became more obvious. The group median measures of onset VEPs to 15' were C1 $2 \mu \mathrm{V} @ 69 \mathrm{~ms} \quad(55-108 \mathrm{~ms}), \quad \mathrm{C} 2$ $10 \mu \mathrm{V} @ 90 \mathrm{~ms}$ (77-145 ms) and C3 14 $\mu \mathrm{V} @ 122 \mathrm{~ms}$ (99-200 ms).

Conclusion The ISCEV standard onset VEP best describes the waveform configuration and latency of the onset VEP produced by $60^{\prime}$ checks in adults of more than 40 years of age. The onset VEP waveform produced by $15^{\prime}$ checks is distinguished by more prominent negative $\mathrm{C} 2$ and earlier $\mathrm{C} 1$ and $\mathrm{C} 2$ latencies.

Keywords Pattern onset VEP · ISCEV standard VEP waveform - Waveform maturation · Check size . Age

\section{Introduction}

Three visual stimuli are described in the 2016 ISCEV VEP standard; pattern reversal, pattern onset and flash [1]. Pattern reversal stimulation is the gold standard. A phase-reversing draughtboard produces a pattern 
reversal VEP which is characterised by a positive peak at a latency of $100 \mathrm{~ms}$. This is established by 7 months of age and is highly reproducible across individuals $[2,3]$. Pattern onset and flash stimulation are recommended for patients with active defocus or nystagmus, or to identify chiasmal misrouting in albinism. VEPs produced by pattern onset and flash stimulation have complex polyphasic waveforms and show considerable inter-individual variation [1].

The pattern onset VEP waveform shown in the ISCEV VEP standards has well-described C1-positive-C2-negative-C3-positive peaks [1], but in practice these individual peaks are not always identifiable. Infants, for example, tend to show a single, simplified broad positive peak, which becomes more complex with maturation [4]. There are few published examples of pattern onset VEP waveforms. We sought to better describe and understand the waveform changes that may be expected in pattern onset VEPs produced by different check sizes at different ages when the ISCEV standard protocol is used.

\section{Methods and subjects}

A cross-sectional observational study was carried out. Pattern onset VEPs were elicited from 24 adult subjects aged 20-63 years to the ISCEV standard VEP protocol which stipulates check side lengths $60^{\prime}$ and $15^{\prime}$ presented in a minimum $15^{\circ}$ field recorded from $\mathrm{Oz}$ referred to Fz. The stimuli were presented for $200 \mathrm{~ms}$ onset/followed by $400 \mathrm{~ms}$ offset of mean luminance $82 \mathrm{~cd} / \mathrm{m}^{2}$ on a plasma display panel Michelson contrast $96 \%\left(\max 170 \mathrm{~cd} / \mathrm{m}^{2} / \mathrm{min} 6 \mathrm{~cd} / \mathrm{m}^{2}\right)$ viewed at $1 \mathrm{~m}$. Pattern onset VEPs were additionally recorded from 5 adults who viewed the same stimuli in a larger $30^{\circ}$ field and with a shorter onset period of $200 \mathrm{~ms}$ and from 10 teenagers to $60^{\prime}$ checks presented with an additional, longer inter-stimulus interval/offset interval of $1000 \mathrm{~ms}$

Pattern onset VEPs recorded from Oz-mf 16 infants aged 7 months were retrospectively reviewed from a sample of more than 200 infants who were tested within the first year of life when laboratory reference data were compiled. The age 7 months was selected because it is the age at which pattern reversal p100 latencies fall within $10 \%$ of adult values. Onset VEPs in this infant reference study typically were recorded using a wider range of check sizes, 400', 200', 100', $50^{\prime}, 25^{\prime}$ and $12.5^{\prime}$ presented for $230 \mathrm{~ms}$ in a $30^{\circ}$ field followed by a field of mean luminance for $330 \mathrm{~ms}$. For this study, the stimuli had been displayed on a $74-\mathrm{cm}$ NEC multi-synchronisation monitor (contrast $80 \%$ and luminance $50 \mathrm{~cd} / \mathrm{m}^{2}$ ).

The acquisition trigger timing, field size and check sizes presented on the plasma display panel were adjusted to match the NEC monitor. All data were recorded using the Espion system. The EEG was digitised using a sampling rate of $1 \mathrm{kHz}$ and a bandpass filter of 0.312-100 Hz. The amplifiers had a fixed gain with an input range of $\pm 0.5 \mathrm{~V}$ (Espion by Diagnosys, Cambridge, UK). The impedances of all electrodes were balanced and maintained below $5 \mathrm{k} \Omega$ throughout the recordings. In all cases, central fixation was monitored by CCTV.

The onset VEP waveforms were evaluated and the amplitude and latency of the main peaks and troughs measured. In cases where $\mathrm{C} 1-\mathrm{C} 2-\mathrm{C} 3$ morphology was not defined, the first main positive peak was taken as $\mathrm{C} 1$. In cases where $\mathrm{C} 1$ was not identified, but a negative $\mathrm{C} 2$ was prominent, the time point at the beginning of the $\mathrm{C} 2$ descent from baseline was taken as a $\mathrm{C} 1$ latency.

\section{Results}

Pattern onset waveforms examples from healthy infants are shown in Fig. 1. Data from 16 infants aged 7 months, the age at which reversal VEPs are within $10 \%$ of adult latency [3], are shown in Fig. 2a, b.

At 7 months 13/16, infants showed an early positive peak mean C1 $13 \mu \mathrm{V} @ 94 \mathrm{~ms}$ (range 76-112 ms), seen in the top Fig. 2b. Of 13, 5 showed only the early positive peak, but $8 / 13$ showed a positive peak at $138 \mathrm{~ms}$ as well (middle trace Fig. 2b). Of 16, 3 infants showed only a later positive peak (possibly C3), mean $135 \mathrm{~ms}$ (range 130-138 ms) bottom trace Fig. $2 \mathrm{~b}$.

Adult pattern onset VEP waveforms are arrayed in broad decade panels in Fig. 3. The ISCEV standard pattern onset VEP C1-C2-C3 configuration is seen more consistently after 45 years to $60^{\prime}$ checks (Fig. 3c). The $\mathrm{C} 2$ trough is more prominent in the pattern onset VEP waveform produced to smaller $15^{\prime}$ checks. $\mathrm{C} 1$ and $\mathrm{C} 2$ latencies are earlier to $15^{\prime}$ checks compared to $60^{\prime}$. The teenage pattern onset VEPs to $60^{\prime}$ were similar to those of the 20 year old shown in Fig. 3, a simple positive peak (Fig. 4).

The latency range of pattern onset VEP main peaks produced by $60^{\prime}$ and $15^{\prime}$ checks is detailed in Table 1 . 


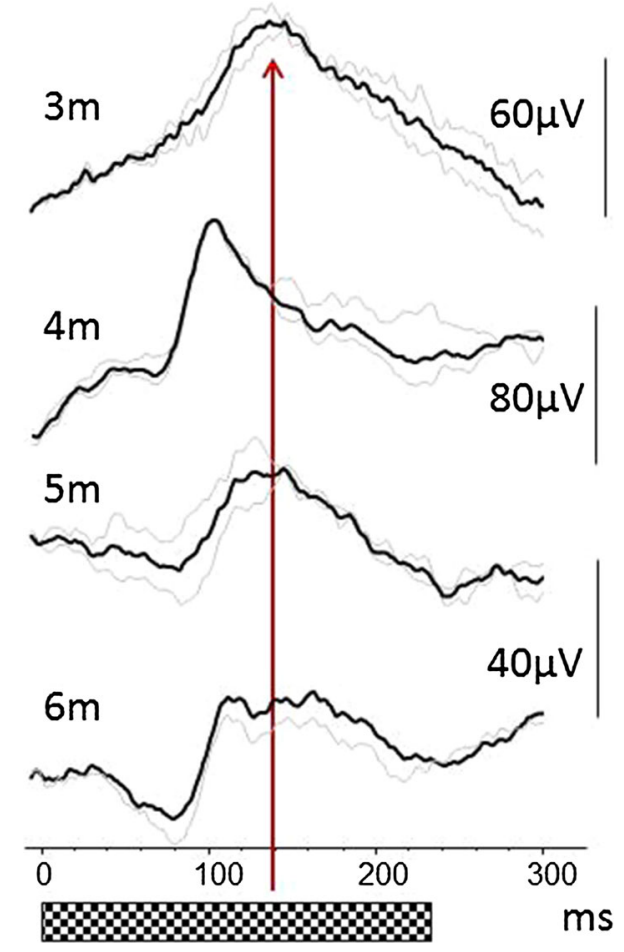

Fig. 1 Example pattern onset VEPs waveforms from infants aged 3, 4, 5 and 6 months show a trend for the positive peak latency to reduce from 140 to $100 \mathrm{~ms}$. The solid line is the average, repeated trials are shown in grey

When the latency ranges are translated onto the standard ISCEV onset VEP waveform in Fig. 5, there is good agreement with the $60^{\prime}$ check values.

We also compared the onset waveforms from the same adults produced by the ISCEV standard field size $15^{\circ}$ with those from checks presented with a slightly longer onset period of $230 \mathrm{~ms}$ in a larger $30^{\circ}$ field. Though waveforms differed within the same individual to $60^{\prime}$ or $15^{\prime}$, we did not observe an intra-individual difference between the onset VEP waveforms produced when either of these checks was presented in $15^{\circ}$ or $30^{\circ}$ field, nor did we observe any differences in the onset VEP waveform elicited to $200 \mathrm{~ms}$ compared to $230 \mathrm{~ms}$ onset, nor when the inter-stimulus interval/ offset interval was $330 \mathrm{~ms}$ cf $1000 \mathrm{~ms}$.

\section{Discussion}

Pattern onset stimulation is an essential VEP stimulus for paediatric clinics where defocus and nystagmus are often encountered. The ISCEV VEP standard recognises that inter-individual variability of VEP waveforms produced by onset and flash stimulation is high [1], but the within individual concordance means that an inter-ocular comparison of onset and flash VEP waveforms can provide valuable clinical information, as can an inter-ocular comparison of the transoccipital distribution of monocular responses. Indeed onset stimulation is required for detection of chiasmal misrouting of albinism in older subjects [4-7].

Published illustrations most often show onset VEP waveforms with $\mathrm{C} 1: \mathrm{C} 2: \mathrm{C} 3$ ratios that resemble the ISCEV standard waveform example [1]. Our findings caution that the composition of the onset VEP waveform is dependent upon age and check size. Our data suggest the onset VEP waveform illustrated in the ISCEV VEP standard [1] most likely represents the response produced by $60^{\prime}$ pattern onset in a 45 year old subject. The onset VEP waveform produced by smaller $15^{\prime}$ checks has a more prominent $\mathrm{C} 2$, compared to $60^{\prime}$, and has earlier $\mathrm{C} 1$ and $\mathrm{C} 2$ latencies. The range of latencies for each component described in our study of ISCEV standard onset VEPs agrees well with other published adult work, e.g. C1 $65-80 \mathrm{~ms}, \mathrm{C} 2$ 90-110 ms, C3 150-200 ms [8] and C1 80-110 ms [9].

Although the $\mathrm{C} 1$ component is better seen in older subjects, it may also be enhanced by rapid onset periods (e.g. $25 \mathrm{~ms}$ onset [10] or $40 \mathrm{~ms}$ onset [11] compared to ISCEV standard $200 \mathrm{~ms}$ ), use of lateral electrodes and large checks [12]. Indeed the spatial tuning of adult onset VEP components is complex; for example, Kriss et al. [8] reported that $\mathrm{C} 1$ is largest to $72^{\prime}, \mathrm{C} 2$ largest to $9^{\prime}$ and $\mathrm{C} 3$ bimodally larger to $9^{\prime}$ and $110^{\prime}$.

The three peaks of the onset VEP, C1, C2 and C3, appear to represent an interaction and temporal summation of activity from different cortical sources. These multiple, simultaneously active areas are very close together. Our data suggest ageing differentially alters the relative contribution of one or each component to the summated onset VEP waveform, but it is challenge to attribute a specific peak to a cortical source. Researchers have sought innovative ways to solve this inverse problem [13]. Parametric manipulations that include contrast adaptation, localising stimulation to small quadratic fields, which show the dependence of the waveform on retinal location, and principal component analyses and coregistration of fMRI, EEG and MEG have been used to infer cortical dipoles [10, 14-17]. 
(a)

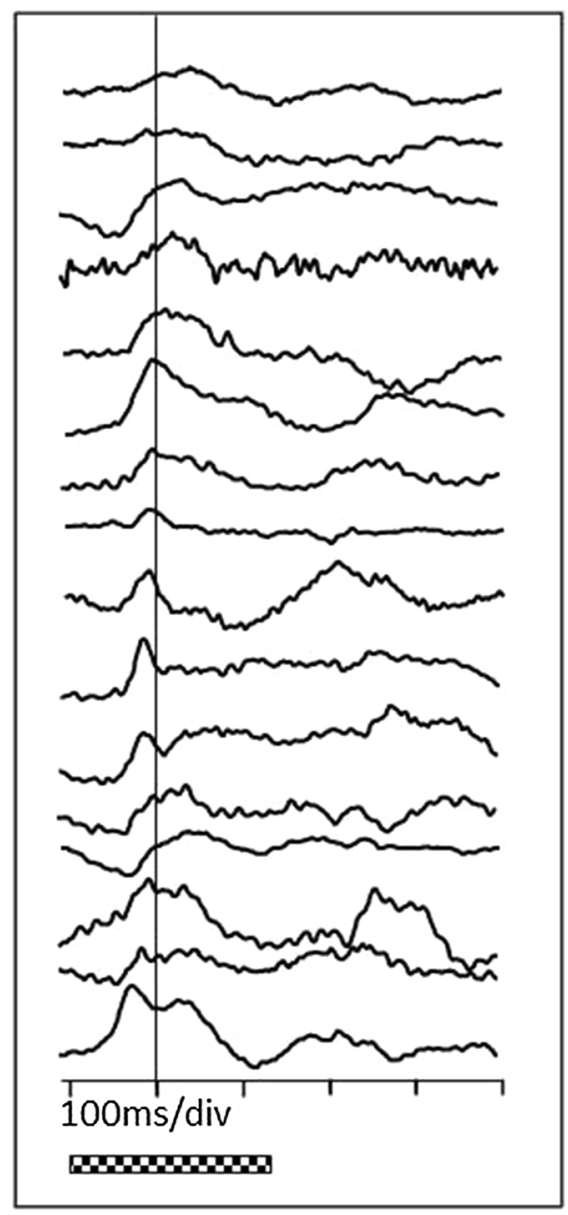

Fig. 2 a Average onset waveforms from 16 individual infants all aged 7 months are arrayed. b Waveforms from 3 infants that exemplify the maximal waveform variation at 7 months are

There is broad consensus that the onset VEP waveform has at least two overlapping time components: one from striate and the other from extra-striate areas [10, 14-17]. Classic studies from Jeffreys and Axford $[10,17]$ attributed $\mathrm{C} 1$ to striate cortex and C2 to extra-striate regions (for comparison $\mathrm{C} 2$ is $\mathrm{P} 1$ in di Russo et al. 2002 description [13]), whilst Spekreijse et al. [18] associated $\mathrm{C} 1$ with local luminance changes within the pattern arising from area 18 and $\mathrm{C} 2$, which is sensitive to contrast, defocus and pattern size, with striate areas [14]. This controversy is current some 50 years later $[19,20]$. Mostly available data suggest C1 arises from multiple visual areas, but has a predominant contribution from V1 primary striate visual cortex in the early part of the waveform, whilst (b)

\section{ISCEV pattern onset VEP}

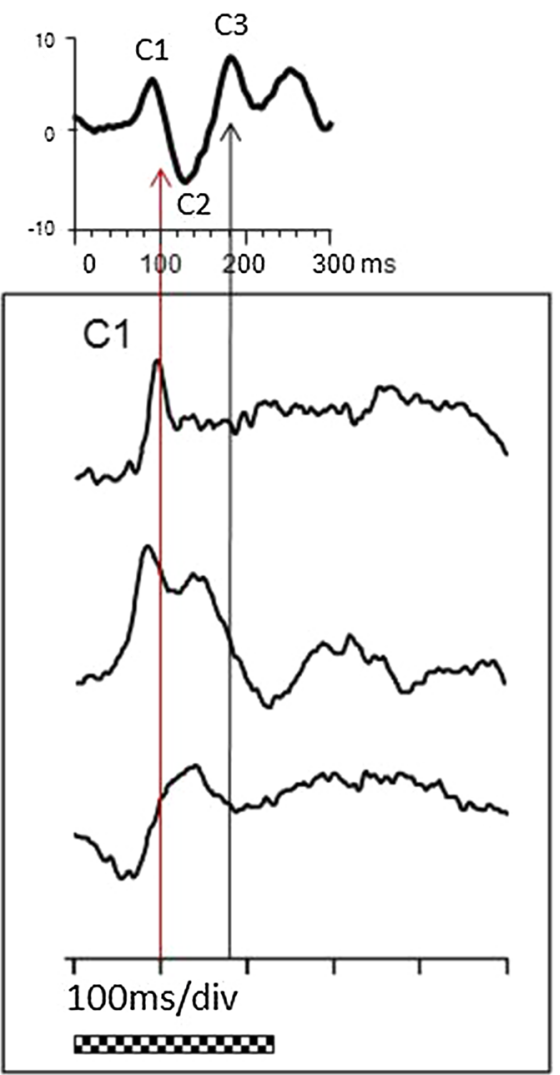

highlighted. The ISCEV standard waveform is shown on the same timescale in black for ease of comparison above

$\mathrm{C} 2$ reflects activity in dorsal and ventral extra-striate and $\mathrm{C} 3$ has also posterior parietal cortex contributions $[21,22]$.

During the early parametric studies two maturational phases for the onset VEP emerged: a rapid phase between birth and 8 months and followed by a slower phase ending at puberty with the $\mathrm{C} 1-\mathrm{C} 2-\mathrm{C} 3$ onset VEP morphology apparent at 16 years [11]. Published figures of paediatric pattern onset VEPs are very few. A population study of 214 children from 2 months to 12 years by De Vries-Khoe and Spekreijse [23] described how a negative peak (C2) became recognisable in the broad positive pattern onset VEP of children, with an incidence increasing continuously from $0 \%$ in the first five to ten months post-term to 
(a)

20-29yrs

$60^{\prime}$ checks

$15^{\prime}$ checks

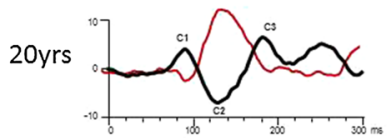

$22 y r s$

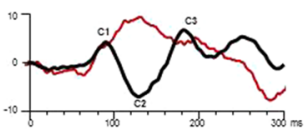

$22 \mathrm{yrs}$

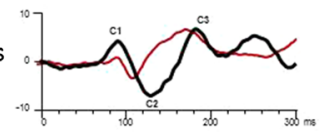

$27 y r s$

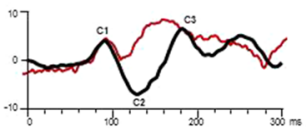

$29 y r s$
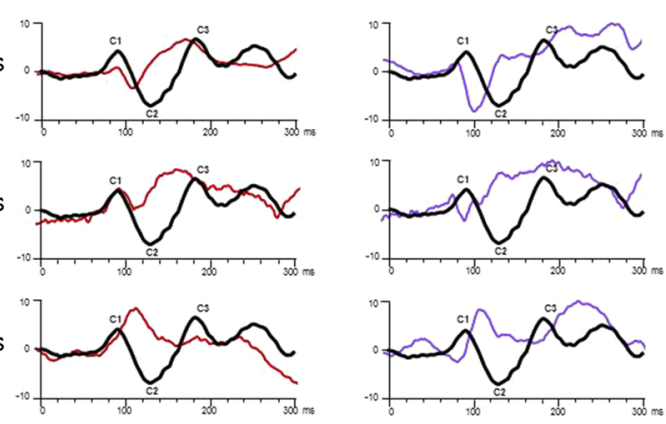

(b)

32-39 yrs

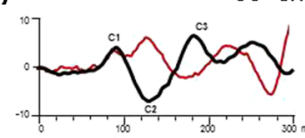

$60^{\prime}$ checks

15' checks

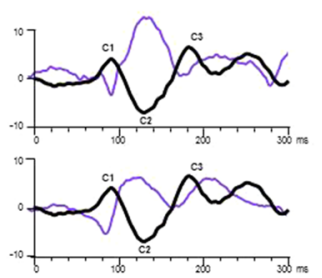

$32 \mathrm{yrs}$
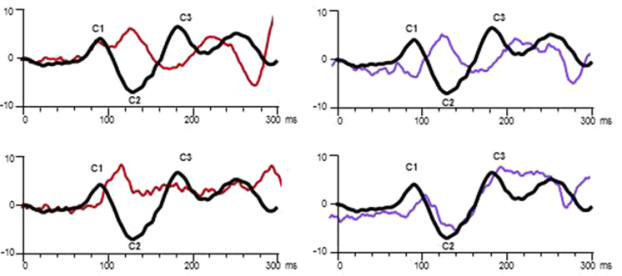

$33 y r s$

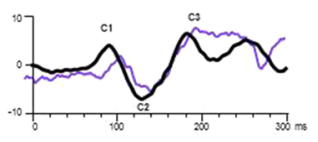

(c)

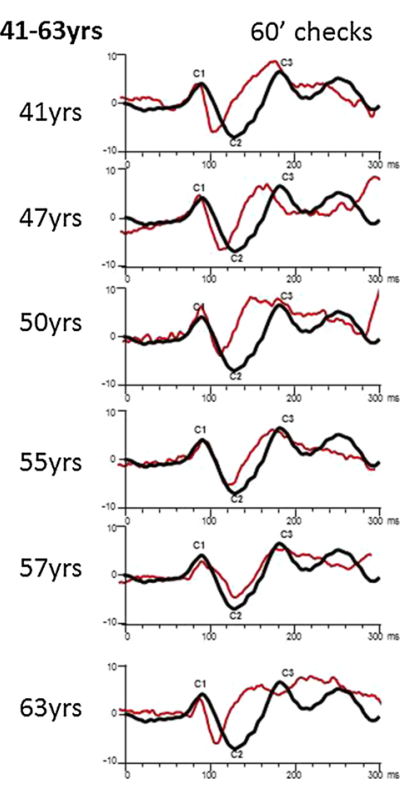

Fig. 3 Three panels of adult pattern onset trace arrays are arranged in decades $(\mathbf{a}-\mathbf{c})$. Onset VEP waveforms produced by $60^{\prime}$ and $15^{\prime}$ checks in the same individual are displayed alongside each other, and each one is superimposed on the ISCEV template waveform in black for comparison. a Adult

about $40 \%$ at 20 months of age and to approximately $100 \%$ around 8 years of age. Ossenblok et al. [24] confirmed this in a detailed study of equivalent dipole source localisation of 10 children aged 6-16 years and described the evolved response as being a positive
$35 y r s$

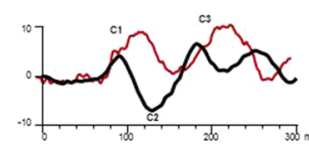

$38 y r s$
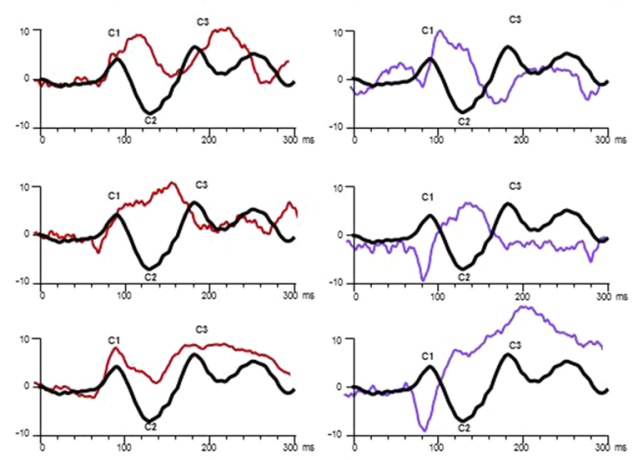

$39 y r s$

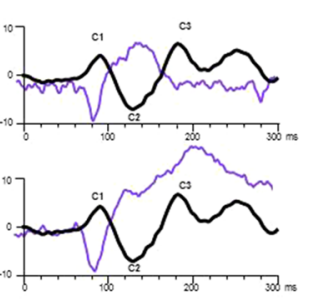

$15^{\prime}$ checks

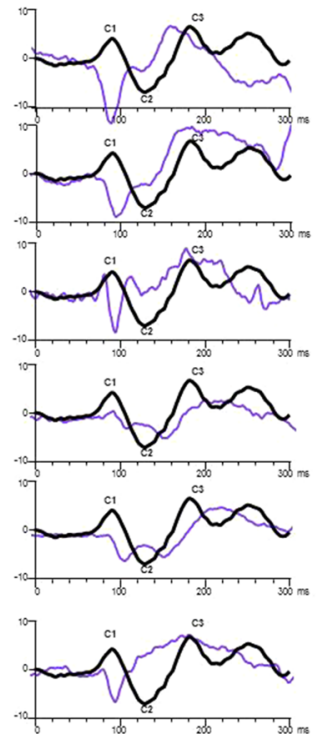

(aged 20-29 yrs), pattern onset waveforms overlaid on ISCEV standard waveform. b Adult (aged 32-39 yrs), pattern onset waveforms overlaid with ISCEV standard. c Adult (aged 41-63 yrs), pattern onset waveforms overlaid with ISCEV standard

peak at $130 \mathrm{~ms}$ preceded by a negativity at $100 \mathrm{~ms}$. These changes in onset VEP waveform from childhood to adulthood were attributed to changes in the activity profile of the striate cortex, which dominates in younger children whilst extra-striate activity 
Fig. 4 Example waveforms from 3 individuals are shown that summarise the main change in waveform features with check size and age during adulthood

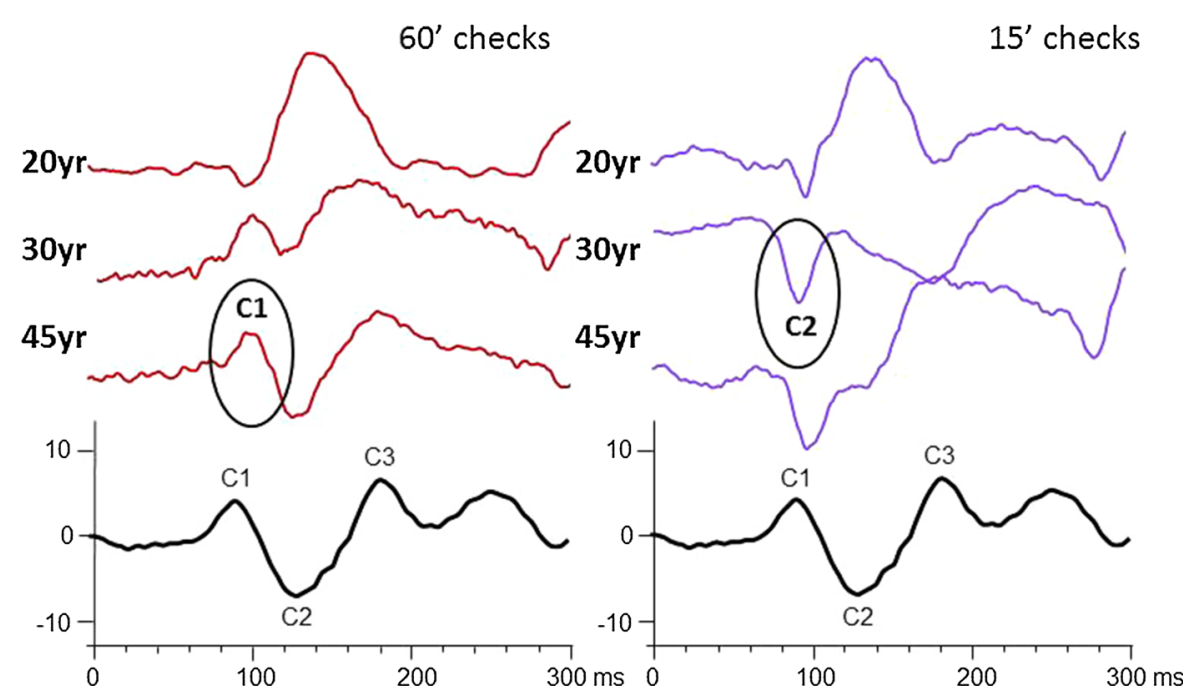

Table 1 The median and range of amplitude and latency of each peak of the pattern onset VEPs produced by $60^{\prime}$ and $15^{\prime}$ checks

\begin{tabular}{lllll}
\hline & $60^{\prime}$ median adult peaks $($ range $)$ & \multicolumn{2}{l}{$15^{\prime}$ median adult peaks $($ range $)$} \\
\hline $\mathrm{C} 1$ & $7 \mathrm{uV} @ 88 \mathrm{~ms}$ & $(69-109 \mathrm{~ms})$ & $2 \mathrm{uV} @ 69 \mathrm{~ms}$ & $(60-95 \mathrm{~ms})$ \\
$\mathrm{C} 2$ & $11 \mathrm{uV} @ 109 \mathrm{~ms}$ & $(109-150 \mathrm{~ms})$ & $14 \mathrm{uV} @ 90 \mathrm{~ms}$ & $(79-143 \mathrm{~ms})$ \\
$\mathrm{C} 3$ & $14 \mathrm{uV} @ 152 \mathrm{~ms}$ & $(127-246 \mathrm{~ms})$ & $14 \mathrm{uV} @ 122 \mathrm{~ms}$ & $(100-167 \mathrm{~ms})$ \\
\hline
\end{tabular}
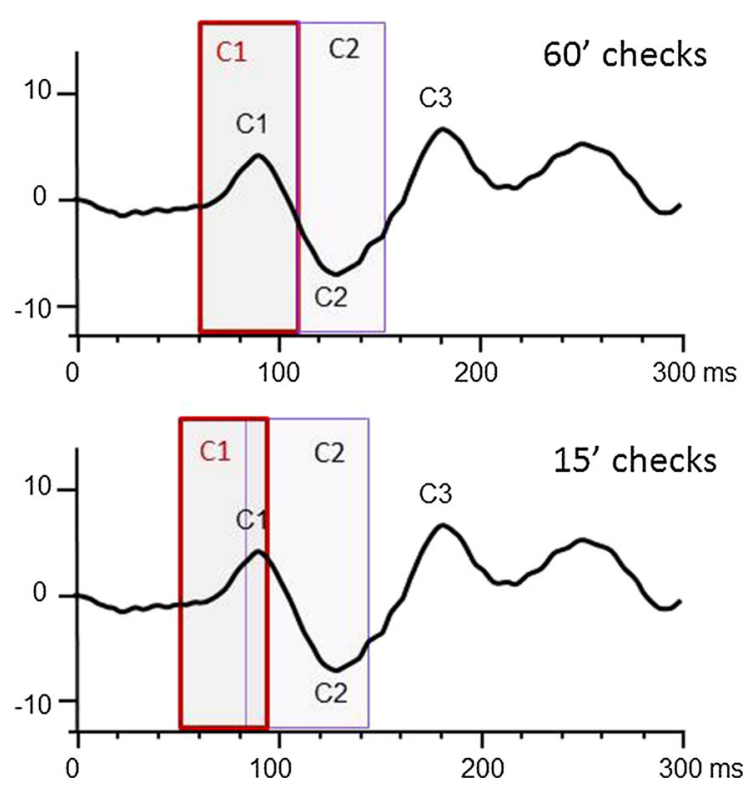

Fig. 5 The latency range of the peaks $\mathrm{C} 1$ and $\mathrm{C} 2$ are displayed over the ISCEV waveform for $60^{\prime}$ and $15^{\prime}$ checks. The peaks to smaller checks are earlier than to larger checks. The ISCEV waveform peaks fall in the middle of the latency range of the adult $\mathrm{C} 1$ and $\mathrm{C} 2$ produced by $60^{\prime}$ check dominates in later life [16]. Apkarian and Tijsson [9] describe the maturation of the albino trans-occipital asymmetry with some waveform illustrations of paediatric onset VEPs. They argued that $\mathrm{C} 2$ is not developed because of the immaturity of the sensitivity to fine elements in the striate cortex, but show $\mathrm{C} 2$ is developed by 20 years (using $12^{\prime}$ checks and $40 \mathrm{~ms}$ onset). They highlighted that reliable contra-lateral asymmetry in the pattern onset VEP is most consistently seen in the $\mathrm{C} 1$ peak-as this is not apparent or well developed in children it helps explain why the flash VEP is a preferred stimulus for checking for albino misrouting in young children under 3 years. Lenassi et al. [25] plotted onset VEP data from 13 children, aged 1 year and less, and suggested mean $\mathrm{C} 1$ latency becomes $\sim 120 \mathrm{~ms}$ at 6 months, with a range $75-155 \mathrm{~ms}$ at 6 years. This agrees with the wide range of peak onset VEP latency in our study of 16 children at 7 months of $76-134 \mathrm{~ms}$. Although there is a preponderance of an early first peak, some waveforms are dominated by later positive peaks.

Surprisingly our study shows a third 'maturational' or differential phase in the onset VEP waveform, or 
rather continuous changes throughout adult life, with the emergence of a more prominent $\mathrm{C} 1: \mathrm{C} 2$ ratio with age. The underpinning physiological changes in the cortex between 40 and 60 years of age responsible for this are unclear and speculative. The occipital lobe is one of the brain areas most resilient to ageing. Myelination and synaptic pruning dominate the maturation changes in childhood whilst neuronal shrinkage and axonal fibre loss predominate ageing. Delineating a transition from maturation to degeneration associated with ageing is complicated to determine in vivo. Grey matter is fairly constant, but white matter volume increases until mid-40s, corresponding with a peak of myelination in some areas at 50 years, e.g. mesial temporal surface [26]. Brain weight is maximal around 20 years and does not reduce until after 50 years with a decline in brain volume starting around 45-50 years [26]. Age-related loss of grey matter is most prominent in the frontal and temporal lobes, with peak loss in dorsal brain areas around 50-70 years. The occipital lobes show least change, and although Good and colleagues [27] describe white matter loss in the occipital cortex, this occurs only towards the eighth and ninth decades. The network of higher-order regions that develop relatively late in adolescence shows accelerated degeneration in old age and heightened vulnerability to disorders that impact brain during adolescence and ageing [28, 29]. According to this 'last in first out' theory, we may speculate that that the onset components associated with extra-striate areas will be affected first by ageing and may underpin the waveform changes we have described.

In terms of VEP generation, these gradual anatomical and physiological changes in cortical tissue could alter extra-cellular or intra-cellular resistance, which in turn may change the relative amplitude and/or timing of one of the components contributing to the summated pattern onset VEP signal. A small latency difference in one component can have a substantial impact on the summated waveform shape, as seen when a 'negative' prolonged on flash ERG is modelled by delaying by $5 \mathrm{~ms}$ the depolarising bipolar contribution to the photopic prolonged on off macaque ERG a-wave [30, 31].

In summary, our data illustrate the changes in the ISCEV standard pattern onset VEP waveform throughout life and provide a template for clinical comparison. Further studies are needed to understand whether these changes may be exploited to explore ageing mechanisms and vulnerability to degenerative disease.

Acknowledgements The Pattern Onset Waveform (POW) study group members from the Clinical and Academic Department of Ophthalmology, Great Ormond Street Hospital London who contributed to this study are Katrina Prise, Victoria Reynolds, Dominique Versace, Sian Handley, Alki Liasis, Josie Evans, Ben Evans, Will Moore, Rob Henderson, Chris Lloyd, Richard Bowman, Lynne Speedwell, Clive Edelsten, Vasiliki Panteli, Jessica Gowing, Rosemary Wilson, Roopen Kuladia, Rachel Wells, Steph Figg, Joanna Randeree, Victoria Smith and Bronwen Walters.

Funding This study was supported by an Ulverscroft Vision Research Studentship awarded to Dennis Fritsch and the National Institute for Health Research Great Ormond Street Biomedical Research Centre (Grant No. 519201).

\section{Compliance with ethical standards}

Conflict of interest The authors declare that they have no conflict of interest. These data were first presented as an oral presentation at the ISCEV scientific meeting Singapore 2016.

Ethical approval All procedures performed in studies involving human participants were in accordance with the ethical standards of the institutional and/or national research committee and with the 1964 Helsinki Declaration and its later amendments or comparable ethical standards. Ethical approval for this registered study 14DS06 was obtained from the Great Ormond Street Hospital Institute of Child Health University College, London, 14/LP2136.

Statement on the welfare of animals This article does not contain any studies with animals performed by any of the authors.

Informed consent Informed consent was obtained from all individual participants included in the study.

Open Access This article is distributed under the terms of the Creative Commons Attribution 4.0 International License (http:// creativecommons.org/licenses/by/4.0/), which permits unrestricted use, distribution, and reproduction in any medium, provided you give appropriate credit to the original author(s) and the source, provide a link to the Creative Commons license, and indicate if changes were made.

\section{References}

1. Odom JV, Bach M, Brigell M, Holder GE, McCulloch DL, Mizota A et al (2016) ISCEV standard for clinical visual evoked potentials: (2016 update). Doc Ophthalmol 133(1):1-9. doi:10.1007/s10633-016-9553-y

2. McCulloch DL, Skarf B (1991) Development of the human visual system: monocular and binocular pattern VEP latency. Invest Ophthalmol Vis Sci 32(8):2372-2381 
3. Kriss A, Russell-Eggitt I (1992) Electrophysiological assessment of visual pathway function in infants. Eye 6(Pt 2):145-153. doi:10.1038/eye.1992.30

4. Kriss A, Russell-Eggitt I, Taylor D (1990) Childhood albinism. Visual electrophysiological features. Ophthalmic Paediatr Genet 11(3):185-192

5. Apkarian P, Reits D, Spekreijse H, Van Dorp D (1983) A decisive electrophysiological test for human albinism. Electroencephalogr Clin Neurophysiol 55(5):513-531

6. Creel D, Spekreijse H, Reits D (1981) Evoked potentials in albinos: efficacy of pattern stimuli in detecting misrouted optic fibers. Electroencephalogr Clin Neurophysiol 52(6):595-603

7. Brecelj J (2014) Visual electrophysiology in the clinical evaluation of optic neuritis, chiasmal tumours, achiasmia, and ocular albinism: an overview. Doc Ophthalmol 129(2):71-84. doi:10.1007/s10633-014-9448-8

8. Kriss A, Spekreijse H, Verduyn Lunel HFE, Braamhaar I, de Waal BJ, Barrett G (1984) A comparison of pattern onset, offset and reversal responses: effects of age, gender and check size. In: Nodar R, Barber C (eds) Evoked potentials 11. Butterworths, New york, pp 553-561

9. Apkarian P, Tijssen R (1992) Detection and maturation of VEP albino asymmetry: an overview and a longitudinal study from birth to 54 weeks. Behav Brain Res 49(1):57-67

10. Jeffreys DA, Axford JG (1972) Source locations of patternspecific components of human visual evoked potentials. II. Component of extrastriate cortical origin. Exp Brain Res 16(1):22-40

11. Apkarian P, Reits D, Spekreijse H (1984) Component specificity in albino VEP asymmetry: maturation of the visual pathway anomaly. Exp Brain Res 53(2):285-294

12. Shawkat FS, Kriss A (1998) Sequential pattern-onset, -reversal and -offset VEPs: comparison of effects of checksize. Ophthalmic Physiol Opt 18(6):495-503

13. Fahle M, Bach M (2006) Origin of visual evoked potentials. In: Heckenlively JR, Arden GB (eds) Principles and practice of clinical electrophysiology of vision, 2nd edn. MIT Press, Cambridge, pp 207-234

14. Maier J, Dagnelie G, Spekreijse H, van Dijk BW (1987) Principal components analysis for source localization of VEPs in man. Vis Res 27(2):165-177

15. Manahilov V, Riemslag FC, Spekreijse H (1992) The Laplacian analysis of the pattern onset response in man. Electroencephalogr Clin Neurophysiol 82(3):220-224

16. Ossenblok P, Reits D, Spekreijse H (1994) Check size dependency of the sources of the hemifield-onset evoked potential. Doc Ophthalmol 88(1):77-88

17. Jeffreys DA, Axford JG (1972) Source locations of patternspecific components of human visual evoked potentials. I. Component of striate cortical origin. Exp Brain Res 16(1):1-21

18. Spekreijse H, van der Tweel LH (1972) System analysis of linear and nonlinear processes in electrophysiology of the visual system II. Proc K Ned Akad Wet C 75(2):92-105
19. Kelly SP, Vanegas MI, Schroeder CE, Lalor EC (2013) The cruciform model of striate generation of the early VEP, reillustrated, not revoked: a reply to Ales et al. (2013). Neuroimage 2013(82):154-159. doi:10.1016/j.neuroimage. 2013.05.112

20. Ales JM, Yates JL, Norcia AM (2013) On determining the intracranial sources of visual evoked potentials from scalp topography: a reply to Kelly et al. (this issue). Neuroimage 64:703-711. doi:10.1016/j.neuroimage.2012.09.009

21. Di Russo F, Martinez A, Sereno MI, Pitzalis S, Hillyard SA (2002) Cortical sources of the early components of the visual evoked potential. Hum Brain Mapp 15(2):95-111

22. Vanni S, Warnking J, Dojat M, Delon-Martin C, Bullier J, Segebarth C (2004) Sequence of pattern onset responses in the human visual areas: an fMRI constrained VEP source analysis. Neuroimage 21(3):801-817. doi:10.1016/j. neuroimage.2003.10.047

23. De Vries-Khoe L, Spekreijse H (1982) Maturation of luminance and pattern EPs in man. Doc Ophthalmol Proc Ser 31:461-475

24. Ossenblok P, Reits D, Spekreijse H (1992) Analysis of striate activity underlying the pattern onset EP of children. Vis Res 32(10):1829-1835

25. Lenassi E, Likar K, Stirn-Kranjc B, Brecelj J (2008) VEP maturation and visual acuity in infants and preschool children. Doc Ophthalmol 117(2):111-120. doi:10.1007/ s10633-007-9111-8

26. Sowell ER, Thompson PM, Toga AW (2004) Mapping changes in the human cortex throughout the span of life. Neuroscientist 10(4):372-392. doi:10.1177/10738584042 63960

27. Good CD, Johnsrude IS, Ashburner J, Henson RN, Friston KJ, Frackowiak RS (2001) A voxel-based morphometric study of ageing in 465 normal adult human brains. Neuroimage 14(1 Pt 1):21-36. doi:10.1006/nimg.2001.0786

28. Raz N, Ghisletta P, Rodrigue KM, Kennedy KM, Lindenberger U (2010) Trajectories of brain aging in middle-aged and older adults: regional and individual differences. Neuroimage 51(2):501-511. doi:10.1016/j.neuroimage.2010. 03.020

29. Douaud G, Groves AR, Tamnes CK, Westlye LT, Duff EP, Engvig A et al (2014) A common brain network links development, aging, and vulnerability to disease. Proc Natl Acad Sci U S A. 111(49):17648-17653. doi:10.1073/pnas. 1410378111

30. Sieving PA, Murayama K, Naarendorp F (1994) Push-pull model of the primate photopic electroretinogram: a role for hyperpolarizing neurons in shaping the b-wave. Vis Neurosci 11(3):519-532

31. Sieving PA (1993) Photopic ON- and OFF-pathway abnormalities in retinal dystrophies. Trans Am Ophthalmol Soc. 91:701-773 